\title{
The role of microenvironment in tumorigenesis: Focus on dendritic cells in human papillomavirus E6, E7-transformed keratinocytes
}

\author{
Marco Iuliano $^{1}$, Giorgio Mangino ${ }^{1}$, Maria Vincenza Chiantore ${ }^{2}$, Gianna Fiorucci ${ }^{2,3}$, Rosita Accardi ${ }^{4}$, Massimo \\ Tommasino $^{4}$, Giovanna Romeo ${ }^{1,3}$ \\ ${ }^{1}$ Department of Medico-Surgical Sciences and Biotechnologies, Sapienza University of Rome, 04100, Latina, Italy \\ ${ }^{2}$ Department of Infectious, Parasitic and Immune-mediated Diseases, Istituto Superiore di Sanità, 00161, Rome, Italy \\ ${ }^{3}$ Institute of Molecular Biology and Pathology, Consiglio Nazionale delle Ricerche, 00161, Rome, Italy \\ ${ }^{4}$ Infections and Cancer Biology Group, International Agency for Research on Cancer, 69372, Lyon, France \\ Correspondence: Giovanna Romeo \\ E-mail: giovanna.romeo@uniroma1.it \\ Received: June 19, 2015 \\ Published online: July 06, 2015
}

\begin{abstract}
The inception of tumor microenvironment (TME), a complex and dynamic system constituted by different types of cells engaged by tumor and extracellular matrix surrounding cancer cells, is a way for them to elude the immune surveillance. Dendritic cells (DCs), as a sentinel, are able to recognize alteration in the microenvironment and predispose the immune system response. The relationship between cancer and virus infection is well documented. High-risk Human Papillomavirus (HR-HPV) has a well-characterized transforming property and has been associated with squamous cell carcinoma of the ano-genital and oral tracts. Transforming ability of HR-HPVs is based on the function of E6 and E7 viral oncoproteins, which interact and inactivate $\mathbf{p} 53$ and pRb oncosuppressors, respectively. Recently, it was demonstrated that HPV oncoproteins are also able to affect a number of microRNAs (miRNAs) regulating the expression of genes involved in proliferative control. For these reasons DC-based vaccines targeting oncogenic E6 and E7 are ideal candidates to elicit strong immune responses. Here we summarize significant data about the analysis of TME in HPV-induced tumorigenesis. We also report original results produced by cytotoxic $T$ lymphocyte (CTL) in vitro priming against E6 and E7 HPV16 antigens, performed using human monocyte-derived dendritic cells. Dendritic cells, maturated by the exposition to necrotic or apoptotic keratinocytes expressing both oncoproteins of HPV16, show different expression levels of specific maturation markers. Evidence indicating the ability of necrotic keratinocytes to alter the microRNA profile in DCs, macrophages (MФ) and Langerhans cells (LCs) compared to prototypical stimuli as bacterial lipopolysaccharide was also provided. We can speculate that, based on transformed cells death pathway (i.e. apoptosis versus necrosis), virus-induced immune alterations might show different results in creating an immunotolerogenic microenvironment during the carcinogenesis process.
\end{abstract}

Keywords: Tumor microenvironment; Human Papillomavirus; dendritic cells; miRNA

To cite this article: Marco Iuliano, et al. The role of microenvironment in tumorigenesis: Focus on dendritic cells in human papillomavirus E6, E7-transformed keratinocytes. Can Cell Microenviron 2015; 2: e874. doi: 10.14800/ccm.874.

\section{Introduction}

The inception of tumors is a process not yet well understood that requires a subversion of the immune system
[1]. It is not clear the exact order of events initiating a tumor, but it is critical the concomitant presence of mutations in oncogenes or tumor-suppressor genes in a tissue cell and settle of chronic inflammation ${ }^{[2]}$ that directly and indirectly 
create a mutagenic microenvironment [3]. Tumor microenvironment (TME) is a complex and dynamic system constituted by different types of cells engaged by tumor cells (fibroblasts, endothelial cells, smooth muscle cells, granulocytes, B, T and Natural Killer lymphocytes, mast cells, macrophages and dendritic cells) and extracellular matrix surrounding cancer cells ${ }^{[2,4,5]}$. Cancer cells secrete cytokines and chemokines to modulate TME and to recruit immune cells for regulating tumor development. These tumor cells-derived cytokines could, depending on the case, reinforce or repress the inflammatory microenvironment, suppress the activation of anti-tumor immune cells promoting at the same time angiogenesis, tumor cells invasion, mobility, extravasation and intravasation in metastatic site ${ }^{[2,6,7]}$.

During the cancer initiation, TME is composed of inflammatory factors, like damage-associated molecular patterns (DAMPS), pathogen-associated molecular patterns (PAMPS) and cytokines as TNF- $\alpha$, IFN- $\gamma$, IFN- $\alpha / \beta^{[8-10]}$, that chronically stimulate cells of the innate and adaptive immune system. Once tumors have established, TME changes, becoming constituted by immune modulatory cytokines like IL-4, IL-13 and growth factors like colony stimulating factor-1 (CSF1) and granulocyte/macrophage colony stimulating factor-1 (GM-CSF) leading to an immune suppressive environment ${ }^{[2]}$.

Macrophages and dendritic cells (DCs) play a central role among the immune cells recruited in the TME. These cells are characterized by high diversity and plasticity ${ }^{[4]}$. In addition, they recognize different external stimuli redefining in this way their transcription profile. Receptor engagement typically leads to the activation of multiple signal transduction pathways ${ }^{[11]}$ that results in a response in DCs which is dependent on the peculiar transcriptional cascade activated. This temporal cascade leads to the expression of transcription factors, signaling molecules, cytokines, chemokines, effector proteins and regulators of metabolism, cell growth and cell survival that, possibly, determinate the immune response ${ }^{[12]}$. Recently, it was demonstrated that such expression is also modulated by microRNAs (miRNAs). MiRNAs have unique expression profiles in cells of the innate and adaptive immune systems and have critical roles in modulating cell differentiation, lineage specification, and effector functions ${ }^{[13]}$. Indeed, the engagement of pattern recognition receptors (PRRs) by their PAMPs agonists regulates the expressions of several miRNAs both by up- or down-modulating them. Many of these miRNAs target the expression of PPRs themselves as well as of different signaling intermediates and transcription factors involved in the activation of macrophages or in DCs activation and maturation ${ }^{[14]}$. Therefore, they play a pivotal role in the negative regulation of these functions thereby dampening pro-inflammatory state and/or avoiding autoimmune responses. DCs are fundamental to the beginning of tumor-specific immune responses. Understanding the TME role and its composition is necessary to increase the success of DC-based therapies ${ }^{[15]}$. Indeed, a DCs feature is to present to $\mathrm{CD}^{+} \mathrm{T}$ cells fragments of exogenously acquired antigens, loaded into peptide/MHC class I complexes, in a process called cross-presentation ${ }^{[16,17]}$. Recently, some studies have underlined how the capability of any subset of DCs to cross-present antigens in an optimal way is linked to the "quality" of DC activation ${ }^{[18,19]}$. Inflammatory cytokines, CD40 signaling (as provided by helper $\mathrm{CD}^{+} \mathrm{T}$ cells) and Toll-like receptor ligands can decide the maturation fate of DCs and consequently prime them for antigen cross-presentation ${ }^{[20,21]}$. As stated before, DCs exhibit on plasma membrane distinct classes of PRRs to detect the "signal 0" or, rather, the recognition of the danger factors. These PRRs include the nucleotide oligodimerization domain (NOD)-like receptors (NLRs), retinoic acid-inducible gene-1 (RIG-1)-like receptors (RLRs), absent in melanoma 2 (AIM2)-like receptors (ALRs), the receptor for advanced glycation end products (RAGE) and toll-like receptors (TLRs) ${ }^{[11,22]}$.

According to a recent technique, DCs are directly isolated from cancer patients thereby by-passing the immune suppressive action of TME. The protocol based on these DCs was applied to specifically prime in vitro CTLs against different tumor-associated antigens, such as cancer-testis, tumor-mutated or aberrantly expressed normal genes as well as genes encoding viral proteins ${ }^{[23]}$. Various procedures exist to prime DCs in order to properly mature them, for stimulating an effective antigen specific CTL immune response, even if the obtained results are discordant ${ }^{[24-30]}$. In one of these methods, tumor cells are killed ex vivo and used to mature DCs. Cancer cells can die via different mechanisms, including necrosis and apoptosis. While necrosis is caused by injury or strong stress of the cell and is characterized by collapse of cell membrane integrity and a release of DAMPS [31], apoptosis is the process of programmed cell death triggered by several signals resulting in a high regulated process of intracellular destruction [32, 33] The main characteristic of apoptotic cells is the maintenance of membrane integrity, at least in the first phase of the process, that prevents the release of danger signals ${ }^{[34]}$.

Apoptotic and necrotic cells possibly produce different molecular inputs leading to divergent DC maturation and, by consequence, elicitation of immune responses ${ }^{[35]}$ : necrotic cells induce immune stimulation, whereas apoptotic cells induce tolerance ${ }^{[36,37]}$. By contrast, a new concept of cell death is arising: the cells can die in immunogenic cancer cell 
death (ICD) or non-immunogenic cancer cell death (NICD) $[38,39]$, depending on the lethal stimulus that they have received ${ }^{[39-41]}$. Danger-associated molecular patterns, such as heat-shock proteins (HSPs), high mobility group box 1 (HMGB1) and ATP, are important in producing ICD. They are released, secreted or exposed on the plasma membrane in response to stress or death ${ }^{[35]}$. Interestingly, pre-apoptotic tumor cells can expose or secrete/release them ${ }^{[42]}$. Moreover, at late phase of apoptosis (also called secondary necrosis), the cell membrane looses integrity and DAMPs are released thus producing high ICD. This scenario helps to better understand why, in several studies, DCs loaded with apoptotic cells were more effective than DCs loaded with necrotic cells at eliciting significant CTL responses in murine models ${ }^{[43-45]}$. Other studies suggest, on the other hand, that necrotic cells are better than apoptotic cells to efficiently stimulate the maturation of DCs by using in vitro pulsing protocols ${ }^{[46]}$.

\section{Tumor Microenvironment in HPV-induced tumorigenesis}

Most of cancers are caused by acquired somatic mutations and environmental factors. Among these factors, chronic infection has been accepted as a major driver of inflammation-induced tumorigenesis. Indeed, up to $26 \%$ of all cases of cancer worldwide are associated with microbial infection and it is plausible that this estimate may be rather low ${ }^{[47-49]}$. Human Papillomaviruses (HPVs) are small DNA viruses associated with the risk to develop both benign and malignant lesions in different anatomic sites. The life cycle of HPVs appears strictly correlated to the differentiation program of keratinocytes. The virus is able to infect the basal layer of the squamous epithelium and to initiate a producing persistent infection favoring tumor development by deregulating cell proliferation and inhibiting apoptosis ${ }^{[50]}$. High-risk Human Papillomaviruses (HR-HPVs) are the etiological agent of cervical cancer and are responsible for about $20 \%$ of all human tumors associated with infection. Every year, more than 500,000 new cervical cancer cases and 275,000 deaths are recorded in the world ${ }^{[23]}$.

HR-HPV oncoproteins E5, E6 and E7 are the primary viral factors responsible for initiation and progression of cervical cancer ${ }^{[51]}$. However, they are necessary but not sufficient to the tumor development. Indeed, in order to obtain the transformation of the epithelial host cells, the capability of HR-HPVs to inhibit the immune response, impair cellular gene expression and promote epigenetic mutations ${ }^{[52-54]}$ appears necessary.

The persistent infection of HPVs is a promoter of chronic inflammation. In particular, HPVs have the capability to deregulate TLR expression. TLRs mediate inflammation and their expression occurs in tumor, immune, and stromal cells, which are all known to facilitate chronic inflammation that primes the tumor microenvironment for more aggressive disease phenotypes. TLR activation mediates immune suppression and reduces tumor surveillance. In cancer, the TLRs have emerged as important participants in shaping the tumor microenvironment as they mediate both pro- and anti-tumorigenic pathways ${ }^{[55]}$. It has been reported that HPV16 E7 can down-regulate the expression of TLR-9, an innate immune receptor that recognizes unmethylated double-stranded DNA CpG motifs in the genome of HPV. In order to suppress TLR-9 expression, E7 oncoprotein induce a transcriptional repressive complex, composed by NF- $\mathrm{BB}$ p50-p65, ER $\alpha$, and chromatin modifying enzymes [48]. Proinflammatory cytokines and chemokines, such as IL-1 $\beta$ and CCL5 are inhibited by HR-HPV16 and 18 to favor viral persistence ${ }^{\text {[56] }}$. Moreover, HPV16, 18 and 31 are able to impair the function of the Interferon (IFN) inducible antiviral genes like Interferon-induced protein with tetratricopeptide repeats 1 (IFIT1) and Interferon-induced GTP-binding protein (MX1), proapoptotic genes (i.e. TRAIL and XAF1), and pathogen recognition receptors like TLR3, RIG-I, and MDA5 ${ }^{[57]}$. In addition, in cervical cancer as well as in other tumors, the expression of different miRNAs is considerably modified. In particular, miRNAs with anti- or pro-tumorigenesis properties seem to be affected by oncogenic HPVs principally through the activity of E6 and E7 viral oncoproteins ${ }^{[58,59]}$. Among the miRNAs which are deregulated in HPV-induced transformed cells it is important to highlight miR-21, miR-34a, miR-98, miR-146a, miR-155 and miR-223 because their expression is regulated by TLR-signaling pathways or vice versa.

\section{Research Aim}

The aim of this study was to understand how dendritic cells are influenced in their differentiation and maturation during the E6 and E7 HR-HPV mediated transformation. To achieve this goal we evaluated the ability of DCs to differently recognize necrotic or apoptotic material derived from keratinocytes immortalized with HPV-16 E6 and E7 oncoproteins. Moreover, the differences in DC maturation depending on some miRNAs expression have been evaluated.

\section{Results and Discussion}

To evaluate the rate of maturation of the dendritic cells, monocytes from peripheral blood were purified from buffy coat by using, sequentially, cell separation in Ficoll gradient and cell purification with immune-magnetic anti-CD14 microbeads (see Materials and Methods). Subsequently, the purified monocyte population was differentiated in vitro by 


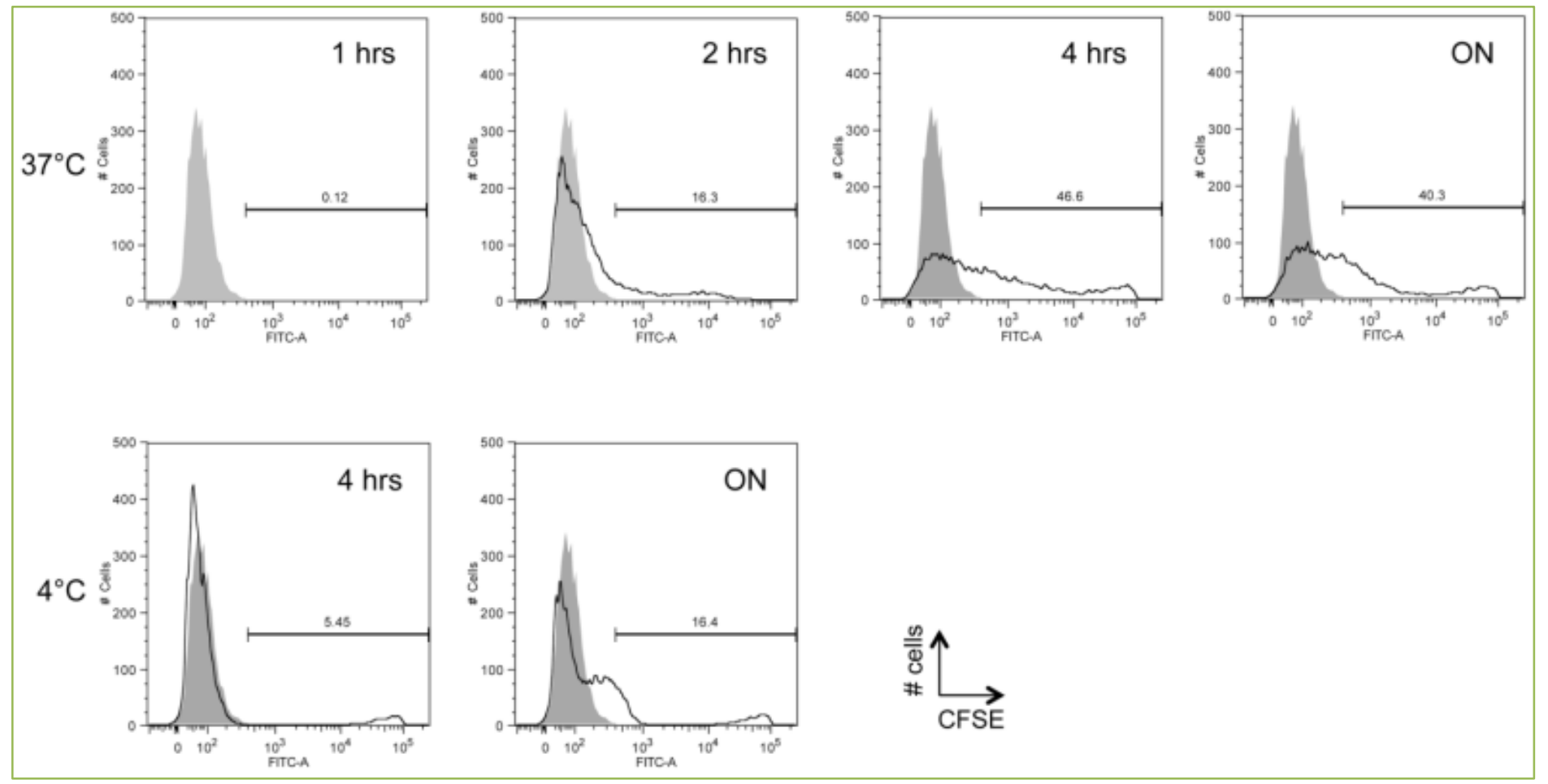

Figure 1. Evaluation of iDCs effectiveness to uptake $\mathbf{K} 16$ fragments. Immature DCs were pulsed at $37^{\circ} \mathrm{C}$ (upper panels) or $4^{\circ} \mathrm{C}$ (lower panels) for 1, 2, 4, 12 hours with $\mathrm{K} 16$ apoptotic bodies derived from K16 cells incubated with CFSE $(0.3 \mathrm{nM})$ at $37^{\circ} \mathrm{C}$ for $10 \mathrm{~min}$ and then induced to apoptotic death by hydrogen peroxide $(0.9 \mu \mathrm{M})$.

the addition of granulocyte-macrophage colony-stimulating factor (GM-CSF) and interleukin 4 (IL-4) in the monocyte culture medium for 5 days of stimulation to achieve immature monocyte-derived dendritic cells (iMDDCs).

\section{Monocytes-derived dendritic cells are able to uptake extracellular K16}

The main characteristic of the iMDDCs is the ability to uptake extracellular material by using several types of mechanisms, even if this feature depends on the effectiveness of the differentiation stimuli ${ }^{[60]}$.

To evaluate whether the differentiation protocol generates iMDDCs able to uptake material from our cell system, we perform a flow cytometry assay of internalization of CFSE-labeled apoptotic bodies from keratinocytes immortalized by transduction with a recombinant HPV16 E6/E7 expressing pLXSN retrovirus (K16 cells). As shown in fig.1, iDCs acquire the highest percentage of fluorescence after 4 hours of pulsing. The internalization of K16 derived apoptotic bodies is an active process because it was reduced when the incubation was performed at $4^{\circ} \mathrm{C}$ rather than at $37^{\circ} \mathrm{C}$. Moreover, the percentage of CFSE-positive iDCs does not change significantly after ON incubation of DC with CFSE-labeled apoptotic bodies. This is probably due to the induction of the maturation process of the iDCs following to the apoptotic bodies uptake and processing. Taken together, these results show the ability of iMDDCs to uptake extracellular K16 cells.

\section{Apoptotic or necrotic $\mathrm{K} 16$ cells lead to a different maturation pattern of iDCs}

Dendritic cell maturation consists of a series of cellular processes that occur in the iDCs subsequent to the recognition of danger molecules or extracellular antigens by one or more receptors on the surface of their plasmatic membrane. This phase in the immune response is called "signal 0" because every mediator, cell and part of cell composing the microenvironment surrounding the iDCs is a potential main character in the effectiveness of the dendritic cell maturation for innate immune or adaptive immune response or for immune tolerance ${ }^{[61]}$.

Once established that 48 hours of iMDDCs pulsing with K16 material is the best time for theirmaturation (data not shown), we evaluated whether necrotic fragments or apoptotic bodies derived from K16 cells are able to induce DCs maturation. The fig.2 shows expression levels of the maturation markers CD83 and CD86 and of the MHC-I. Immature DCs pulsed with K16 apoptotic bodies show a higher expression of MHC-I than iDCs pulsed with K16 necrotic fragment, whereas the expression level of CD86 is 


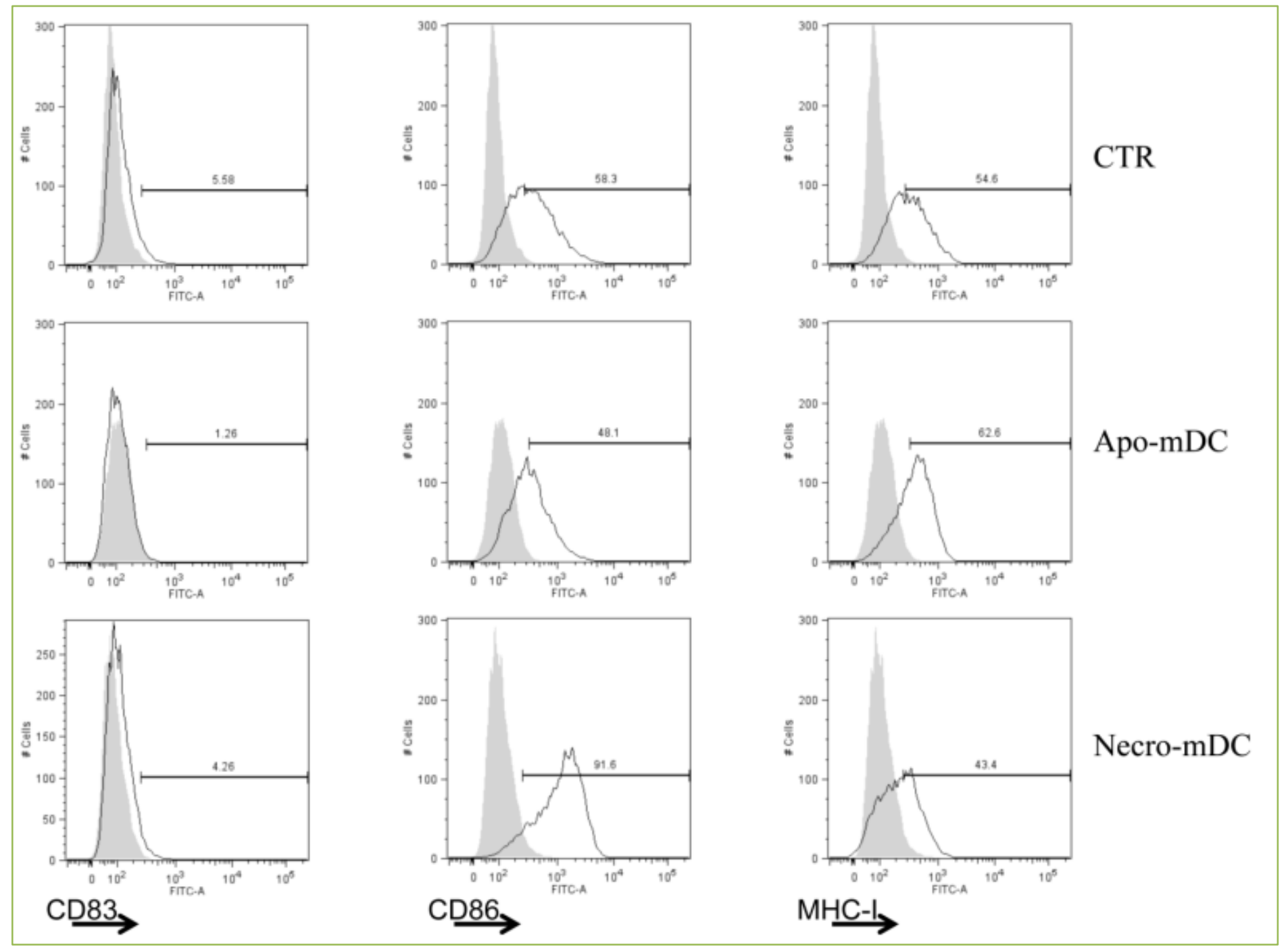

Figure 2. Analysis of the expression levels of DC maturation markers in apo-mDCs and necro-mDCs. Immature DCs were pulsed with K16 apoptotic bodies or K16 necrotic bodies for 48 hours. Necrotic K16 cells were obtained by 3 cycles of rapid freeze/thaw. The expression levels of CD83, CD86 and MHC-I were assessed to evaluate the DCs maturation.

highest in cells incubated with necrotic fragments.

\section{$\mathrm{CDB}^{+} \mathrm{T}$ cells activation does not change on the basis of DC maturation stimulus}

To date there are no assays able to check cross-presentation of exogenous added antigens to $\mathrm{mDC}$. This leads to analyze it only by indirect methods, such as quantification of interferon- $\gamma$ (IFN- $\gamma)$ secretion by mDC-stimulated CD8 ${ }^{+} \mathrm{T}$ cells or by cytotoxic $\mathrm{T}$ lymphocytes (CTLs) functional assay ${ }^{[16]}$.

An effective $C D 8^{+} \mathrm{T}$ cells activation requires a strong and durable interaction between the T-cell receptor and the MHC-I/antigenic peptide complex (signal 1), the interaction among co-stimulator molecules on the surface of mature DCs (mDCs) and CTLs (signal 2) and a productive secretion of inflammatory cytokines and chemokines by mDCs, $\mathrm{CD}^{+} \mathrm{T}$ cells and CTLs (signal 3). To evaluate the effectiveness of CTL activation against K16 cells in relation to the type of iDC pulsing, two in vitro priming protocols have been performed. In the first one, $\mathrm{CD}^{+} \mathrm{T}$ cells from peripheral blood mononuclear cells (PBMC) were stimulated by mMDDCs derived from iMDDC pulsed with K16 apoptotic bodies (apo-mDCs) whereas in the second one, $\mathrm{CD} 8^{+} \mathrm{T}$ cells were incubated with iMDDC pulsed with K16 necrotic fragments (necro-mDCs). In both cases cell cultures were supplemented with IL-7 (only during the first round) and IL-2 to support lymphocytes proliferation. At the end of each CTL priming protocol, a flow cytometric, non radioactive, CTL assay was performed using K16 as target cells.

Fig.3 shows an increase of 2.19 times of the $\mathrm{CFSE}^{+} / \mathrm{PI}^{+}$ events in K16 co-cultured with CTLs stimulated with apo-mDCs with respect to control (first lane), while the 


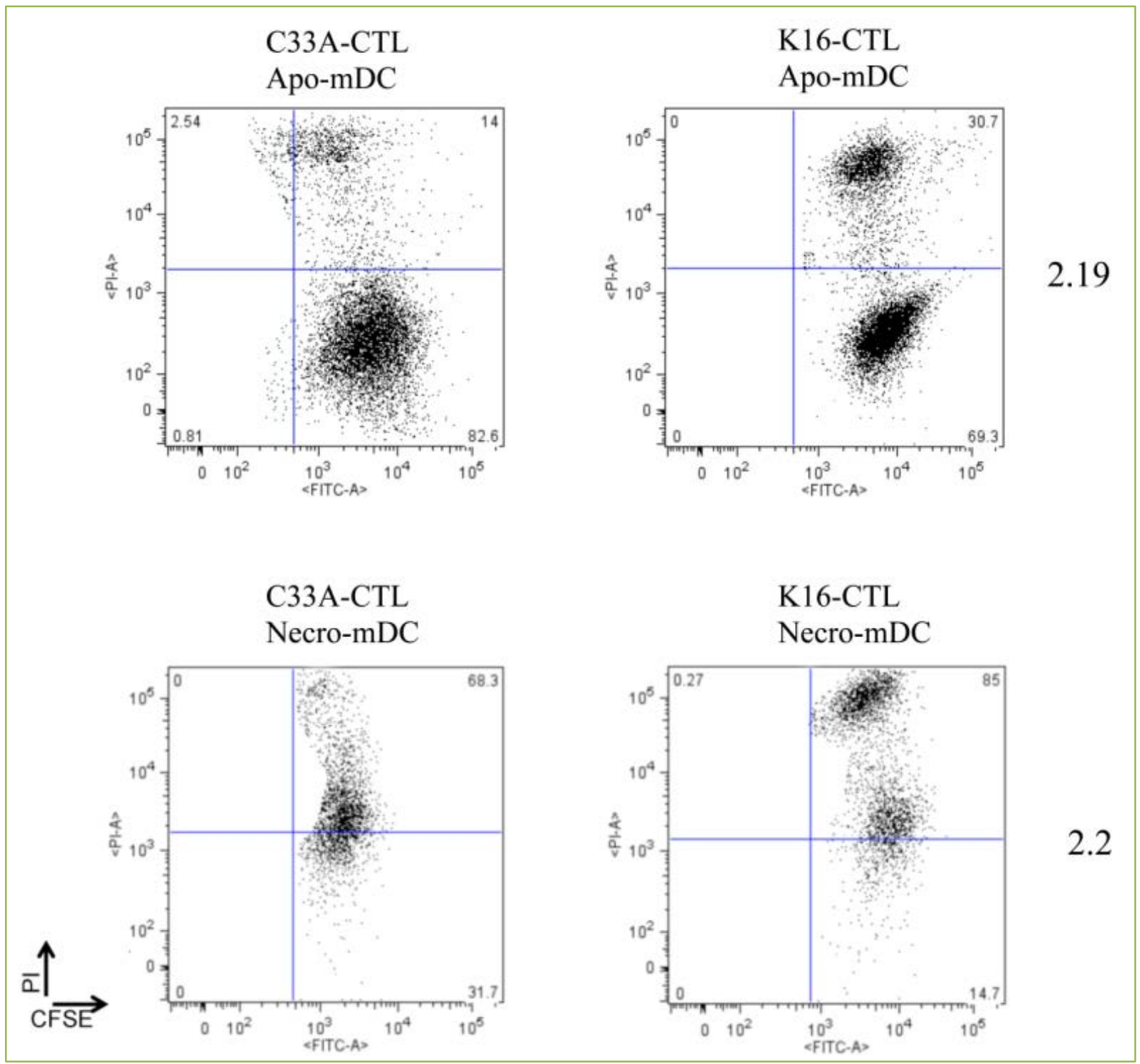

Figure 3. Flowcytometric cytotoxic assay on lymphocytes $\mathrm{T}$ CD8 ${ }^{+}$primed by apo-mDCs or necro-mDCs. The apo-mDCs or necro-mDCs were co-cultured in RPMI-1640 complete medium with IL-2 (50 U/ml) and IL-7 (50 ng/ml) and with autologous peripheral blood lymphocyte (PBL) derived from monocytes-depleted PBMC (responder cells) for a week. Responder cell stimulation was repeated five times for a total of 5 weeks.

increase of the $\mathrm{CFSE}^{+} / \mathrm{PI}^{+}$events in $\mathrm{K} 16$ co-cultured with CTLs stimulated with necro-mDCs is 2.2 times (second line).

These results suggest that the differences on maturation markers expression between necro-mDC and apo-mDC were not linked to a difference in $\mathrm{CD}^{+} \mathrm{T}$ cells activation.

\section{miRNAs expression levels show a representative signature for each APC population}

The APCs are characterized by high diversity and plasticity ${ }^{[4]}$ and TME is composed by different populations of APCs. It is known that there is a continuous communication among cells of the immune system to establish and/or amplify cellular tolerogenic and/or immunogenic functions ${ }^{[62]}$. The perception of "signal 0 " produces different functional responses considering the population of APC. It is important to understand the response of every APC composing the TME to determine the direction of the immune system response. MicroRNAs also participate in directing APCs differentiation and maturation, probably because miRNAs and other epigenetics changes promote plasticity and achievement of a broad range of differentiation fate of APCs ${ }^{[63]}$.

Table 1 resumes some of the most studied miRNAs associated to the regulation of DCs differentiation and maturation. 
Table 1. MiRNAs associated to the differentiation or maturation of DCs and LCs

\begin{tabular}{|c|c|c|}
\hline DENDRITIC CELLS & MATURATION & DIFFERENTIATION \\
\hline miR-146a & ${ }^{[79,80]}$ Taganov 2006, Bai 2012 & \\
\hline miR -155 & $\begin{array}{l}{[13,81-85] \text { Lu 2011, Dunand-Sauthier }} \\
\text { 2011, Zhou 2011, Turner 2011, } \\
\text { Martinez-Nunez 2009 Ceppi 2009 }\end{array}$ & \\
\hline Let-7i & ${ }^{[86]}$ Busch e Zernecke 2012 & \\
\hline $\mathrm{miR}-21$ & & ${ }^{[87,88]}$ Cheng 2010, Hashimi 2009 \\
\hline miR -24 & ${ }^{[89]}$ Fordham 2015 & \\
\hline $\operatorname{miR}-22$ & [90] Liang 2015 & \\
\hline miR -34 & & ${ }^{[87,88]}$ Cheng 2010, Hashimi 2009 \\
\hline $\operatorname{miR}-148$ & ${ }^{[91]}$ Liu 2010 & \\
\hline miR -142-3p & ${ }^{[92]}$ Sun 2011 & \\
\hline miR -30b & [i ${ }^{899]}$ Fordham 2015 & \\
\hline $\mathrm{miR}-106 \mathrm{~b}$ & [93] Tang 2015 & \\
\hline miR -200b & & ${ }^{[94]}$ Liu 2015 \\
\hline LANGERHANS CELLS & MATURATION & DIFFERENTIATION \\
\hline miR -146a & & ${ }^{[95,96]}$ Heinz 2006, Park 2015 \\
\hline miR -155 & ${ }^{[84]}$ Martinez-Nunez 2009 & \\
\hline miR -223 & ${ }^{[97]}$ Mi 2013 & \\
\hline
\end{tabular}

Analysis of miRNA expression has been performed to evaluate how some specific signals produce different responses among several populations of APCs. First of all, three populations of APCs were differentiated starting from peripheral blood monocytes: macrophages (MФ) differentiated in the presence of GM-CSF; DCs differentiated in the presence of GM-CSF and IL-4; Langerhans cells (LCs) differentiated in the presence of GM-CSF, IL-4 and TGF- $\beta$. Each population was maturated by pulsing the cells with necrotic fragment of K16 or, as a positive control, with LPS for 48 hours. We focused our attention on miRNA-146a and miRNA-98 because mir-146a is central in the DCs differentiation and/or maturation ${ }^{[13,64]}$, while mir-98 negatively regulates IL-10 production in macrophages ${ }^{[65]}$. The expression levels of miR-146a and miR-98 were analyzed by Real-Time RT-PCR analysis. Fig. 4 shows an induction of miR-146 expression and a reduction of miR-98 expression in MФ and DCs after LPS stimulation, while miR-146a expression is 11 times increased in LCs stimulated with LPS. Conversely, the trend of the expression levels of miR-146a and miR-98 is similar in DCs and LCs when pulsed with necrotic fragment of K16 cells. МФ exhibit an evident reduction of miR-146a and miR-98 expression. The obtained data confirm how the same stimulus may produce different effects in different populations of APCs.

The development of the tumors create a particular microenvironment leading to the promotion of cancer progression and metastasis hijacking, at the same time, the innate and adaptive immune cells activities ${ }^{[23]}$. Evidence indicates how the DCs are fundamental in such a regulation. Since several studies have shown that vaccination with DCs pulsed with tumor cell lysates could induce significant antitumor immunity ${ }^{[66,67]}$, even if with variables outcomes, it appears fundamental to understand what is the best way to adequately mature DCs in order to obtain a productive $\mathrm{T}$ cells cross-priming. One of the main functions characteristic of DCs is the phenotypic heterogeneity that allows them to respond to the wide spectrum of stimuli composing the TME. Among these stimuli it can be found a plethora of danger signals and molecules linked to cell death. Until now, among the different types of cell death, apoptosis and necrosis are considered the opposite extremes: a programmed cell death versus an incidental cell death. Recently, this difference starts to be smaller, being the necrosis subjected to regulation [68] and apoptosis in late phase showing similitude with necrosis. Evidence from several studies shows how difficult is to establish which is the best type of cell death to produce mature DCs able to stimulate CTL response ${ }^{[43,69-72]}$.

Our data indicate how a DC pulsing with necrotic K16 cells produces mature DCs with expression level of co-stimulatory ligands higher than DCs maturated with apoptotic K16. Conversely, apoptosis seems to be more efficient than necrosis to lead DC maturation toward MHC-I presentation. This consideration enforces the idea that many factors, both DC- and microenvironment-related, regulate DC maturation and that differences between apoptosis and necrosis differentially induce tumor-specific adaptive immune responses ${ }^{[35]}$. In particular, apoptotic cells facilitate the efficient uptake and persistence of the antigen, whereas necrotic cells are more able to secrete DAMPs thereby promoting DCs activation ${ }^{[35]}$. Some other variables, like the duration of the apoptotic stimulus and/or the method used to induce necrosis and apoptosis, have to be evaluated. Indeed, apoptotic cells may undergo secondary necrosis within the DC phagosomes thereby releasing DAMPs with consequent more immunogenic effects ${ }^{[35]}$. Another point to address is which type of "eat me" signals should be exposed to the phagocytes ${ }^{[41]}$. For example, apoptotic cells do not normally release HMGB1, a mediator of recruitment of monocytes and iDC $^{\text {[73] }}$, even after undergoing secondary necrosis, because it 

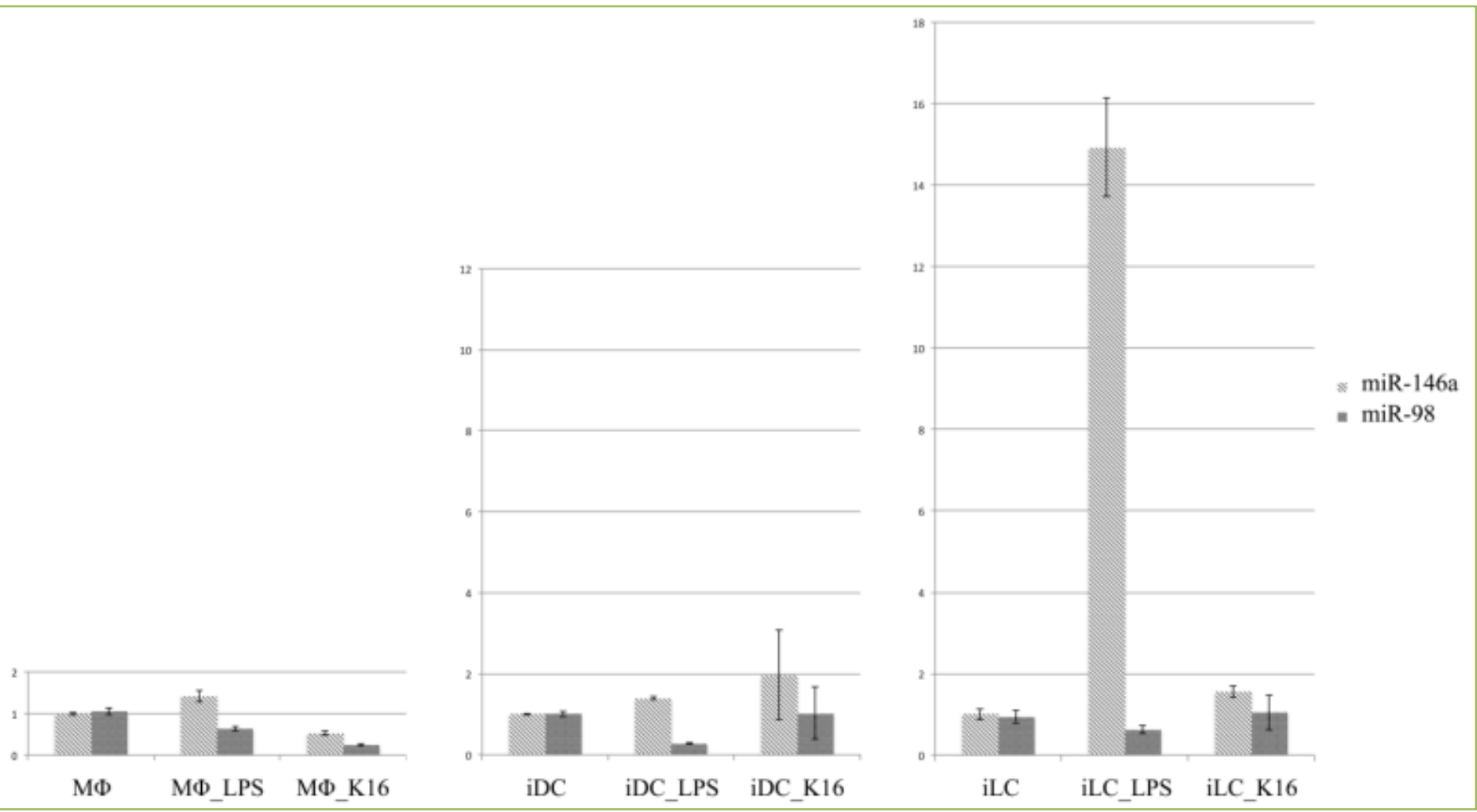

Figure 4. The miR-146a and miR-98 expression levels in macrophages (MФ), immature dendritic cells (iDC) and immature Langerhans cells (iLC) stimulated by LPS or necrotic K16 cells. Macrophages, immature dendritic and Langerhans cells were stimulated for 48 hours with LPS $(10 \mathrm{ng} / \mathrm{ml})$ or K16 necrotic fragments. Total RNA was isolated, miR-98 and miR-146a expression levels were analyzed by Real Time RT-PCR and compared to untreated APCs.

is bound firmly to chromatin ${ }^{[74]}$. Different ways to induce apoptosis could result in a higher release of biologically active HMGB1 and, hence, in a higher immunogenic response.

\section{Materials and Methods}

\section{Cell cultures}

Human Foreskin Keratinocytes were isolated as described by Viac et al. ${ }^{[75]}$. The keratinocytes expressing E6 and E7 proteins of HPV-16 and HPV-38 (K16 and K38 respectively) were obtained by viral transduction of HFK with pLXSN as described by Caldeira at al. ${ }^{[76]}$. All cells were grown at $37^{\circ} \mathrm{C}$ and $5 \%$ of $\mathrm{CO}_{2}$ atmosphere in KBM-Gold media (Keratinocyte Basal Medium,) complemented with KGM-Gold Single Quote Kit (both from Lonza).

The C33A cell line, derived from a biopsy of a cervix tumor ${ }^{[77]}$ and negative for HPV was cultured in RPMI-1640 media complemented with heat inactivated fetal bovine serum (iFBS, Lonza) 10\%.

\section{Monocytes purification and APCs differentiation}

Monocytes purification was performed from Buffy-coat of healthy donor provided by the "Centro di Medicina Trasfusionale, Policlinico Umberto I" in Rome. Peripheral blood mononuclear cells were obtained by centrifugation on Ficoll gradient (Lympholyte-H, Cederlane) and monocytes were isolated by subsequent positive selection using anti-human CD14 magnetic micro-beads (MACS, Miltenyi Biotechology) according to the manufacturer's instructions. Purity of the monocytes preparation was checked by flow cytometry using fluorescein isothiocyanate (FITC)-conjugated anti-CD14 antibody (clone UCHM-1, Becton Dickinson). To induce the differentiation of monocytes in different cellular subpopulations the following cytokines were added in culture for 5 days to RPMI-1640, iFBS 10\%: GM-CSF $50 \mathrm{ng} / \mathrm{ml}$ (PeproTech) to induce differentiation into inflammatory M1 macrophages; GM-CSF $50 \mathrm{ng} / \mathrm{ml}$ plus IL-4 $25 \mathrm{ng} / \mathrm{ml}$ (PeproTech) to induce differentiation to immature DC; GM-CSF $50 \mathrm{ng} / \mathrm{ml}$, IL-4 25 $\mathrm{ng} / \mathrm{ml}$ and TGF- $\beta 15 \mathrm{ng} / \mathrm{ml}$ (PeproTech) to induce differentiation into immature Langerhans cells.

\section{Internalization assay}

K16 cells were incubated with Carboxyfluorescein Succinimidyl ester (CFSE, Invitrogen) $0.3 \mathrm{nM}$ at $37^{\circ} \mathrm{C}$ for 10 
minutes in PBS then extensively washed with PBS 3\% bovine serum albumin (BSA) to remove the excess of CFSE. Apoptosis of K16 was induced by incubating cells for 24 hours in RPMI-1640, iFBS 10\% with hydrogen peroxide 0.9 $\mu \mathrm{M}$. Immature DCs were pulsed with CFSE-labeled K16-derived apoptotic bodies for $1,2,4,12$ hours at $37^{\circ} \mathrm{C}$ or for 4,12 hours at $4^{\circ} \mathrm{C}$. Fluorescence of the immature DCs (iDCs) was evaluated by flow cytometry.

\section{Maturation of the iDCs}

DC maturation was obtained by pulsing iDCs for 48 hours with K16 apoptotic bodies, obtained as described in the previous section, (apo-mDCs), or for 48 hours with K16 necrotic fragments, obtained by 3 cycles of rapid freeze/thaw of K16 cellular pellet resuspended in sterile $\mathrm{H}_{2} \mathrm{O}$, (necro-mDCs). The evaluation of DC maturation was performed by flow cytometry analyses of the following surface maturation markers: CD83 (clone HB15e BD Biosciences - Pharmingen), CD86 (clone BU63 Cymbus Biotechnology) and MHC-I (clone W6/32, Cymbus Biotechnology).

\section{In vitro immunization}

The apo-mDCs or necro-mDCs were co-cultured with autologous peripheral blood lymphocyte (PBL) derived from monocytes-depleted PBMC. The co-culture APC/PBL was performed at 1:10 ratio in RPMI-1640 media complemented with iFBS 10\%, IL-2 50 U/ml (Proleukin, Chiron) and IL-7 $50 \mathrm{ng} / \mathrm{ml}$ (PeproTech). IL-2 was added in culture every 3 days and after 1 week cells were collected and stimulated again with another set of APCs (differentiated and maturated as described before) using the same conditions. Responder cells stimulation was repeated five times for a total of 5 weeks.

\section{Flow Cytometric Cytotoxic assay}

At the end of the fifth round of restimulation, K16 and C33A cells, used as control, were stained with CFSE as already described and used as target cells. Subsequently, targets were co-cultured with responder cells at $37^{\circ} \mathrm{C}$ for 4 hours in a 100:1 ratio responder/target. Finally, cells were counterstained with Propidium Iodide (PI $10 \mu \mathrm{g} / \mathrm{ml}$ ) and analyzed by flow cytometry by measuring the percentage of $\mathrm{CFSE}^{+}$cells able to uptake PI, being only the double positive events the died target cells. The rate of K16 death specifically due to E6/E7 recognition was determined by the difference between the percentage of the $\mathrm{CFSE}^{+} \mathrm{PI}^{+}$of $\mathrm{K} 16$ and control C33A cells.

\section{Flow Cytometry}

All the cytometric analyses were performed on a FACs ARIA II sorter (BD Biosciences). At least 10000 events were recorded for each sample using FACs DiVa software (v6.1.1, BD Biosciences). Data were analyzed using FloJo Software (v8.7, Three Star).

\section{Total RNA extraction, cDNA synthesis and Real-time RT PCR}

Macrophages, dendritic and Langerhans cells were obtained as previously described and were stimulated for 48 hours with LPS (Sigma) $10 \mathrm{ng} / \mathrm{ml}$ or K16 necrotic fragments. Total RNA was isolated using the mirVana ${ }^{\mathrm{TM}}$ miRNA Isolation Kit according to manufacturer's instructions. RNAs were reverse transcribed in $10 \mu \mathrm{l}$ reactions with the relevant specific primer pool of miR-98 and miR-146a (TaqMan MicroRNA Single Assay and Reverse Transcription Kit) according to the manufacturer's instructions. cDNAs ( $4 \mu \mathrm{l}$ of a 1:10 dilution in DEPC- $\mathrm{H}_{2} \mathrm{O}$ ) were quantified in $20 \mu \mathrm{l}$ reactions containing $10 \mu \mathrm{l}$ Universal PCR Master Mix and 1 $\mu \mathrm{l}$ of the individual TaqMan MicroRNA Assay using a 7000HT Fast Real-Time RT-PCR system. Results were analyzed with SDS software (v2.2). All the kits, the Real Time apparatus and the software were from Applied Biosystems. The obtained $C_{T}$ values were converted into $\Delta C_{T}$ values (endogenous control gene: RNU6) and further into $2^{-}$ $\triangle \Delta \mathrm{CT}[78]$. Data were expressed as fold of induction using as comparison no-treated APCs.

\section{Acknowledgements}

Research in our laboratory is funded in part by Research Projects, Sapienza University of Rome, 2013 - 2014.

\section{Conflict of Interest}

The authors have no competing financial interests.

\section{References}

1. Hanahan D Weinberg RA. Hallmarks of cancer: the next generation. Cell 2011; 144:646-674.

2. Noy R, Pollard JW. Tumor-Associated Macrophages: From Mechanisms to Therapy. Immunity 2014; 41:49-61.

3. Dedon PC, Tannenbaum SR. Reactive nitrogen species in the chemical biology of inflammation. Arch Biochem Biophys 2004; 423:12-22.

4. Mantovani A, Biswas SK, Galdiero MR, Sica A, Locati M. Macrophage plasticity and polarization in tissue repair and remodelling. J Pathol 2013; 229:176-185.

5. Gasparini C, Celeghini C, Monasta L, Zauli G. NF-кB pathways in hematological malignancies. Cell Mol Life Sci 2014; 71:2083-2102.

6. Qian BZ, Pollard JW. Macrophage diversity enhances tumor 
progression and metastasis. Cell 2010; 141:39-51.

7. Trikha P, Carson WE. Signaling pathways involved in MDSC regulation. Biochim Biophys Acta 2014; 1846:55-65.

8. Street SE, Cretney E, Smyth MJ. Perforin and interferon-gamma activities independently control tumor initiation, growth, and metastasis. Blood 2001; 97:192-197.

9. Chow MT, Möller A, Smyth MJ. Inflammation and immune surveillance in cancer. Semin Cancer Biol 2012; 22:23-32.

10. Dunn GP, Bruce AT, Ikeda H, Old LJ, Schreiber RD. Cancer immunoediting: from immunosurveillance to tumor escape. Nat Immunol 2002; 3:991-998.

11. Takeuchi O, Akira S. Pattern recognition receptors and inflammation. Cell 2010; 140:805-820.

12. Smale ST, Tarakhovsky A, Natoli G. Chromatin contributions to the regulation of innate immunity. Annu Rev Immunol 2014; 32:489-511.

13. Turner ML, Schnorfeil FM, Brocker T. MicroRNAs regulate dendritic cell differentiation and function. J Immunol 2011; 187:3911-3917.

14. He X, Jing Z, Cheng G. MicroRNAs: new regulators of Toll-like receptor signalling pathways. Biomed Res Int 2014; 2014:945169.

15. Apetoh L, Locher C, Ghiringhelli F, Kroemer G, Zitvogel L. Harnessing dendritic cells in cancer. Semin Immunol 2011; 23:42-49.

16. Joffre OP, Segura E, Savina A, Amigorena S. Nat Rev Immunol 2012; 12:557-569.

17. Steinman RM, Inaba K, Turley S, Pierre P, Mellman I. Antigen capture, processing, and presentation by dendritic cells: recent cell biological studies. Hum Immunol 1999; 60:562-567.

18. Segura E, Durand M, Amigorena S. Similar antigen cross-presentation capacity and phagocytic functions in all freshly isolated human lymphoid organ-resident dendritic cells. J Exp Med 2013; 210:1035-1047.

19. Nierkens S, Tel J, Janssen E, Adema GJ. Antigen cross-presentation by dendritic cell subsets: one general or all sergeants? Trends Immunol 2013; 34:361-370.

20. Dresch C, Leverrier Y, Marvel J, Shortman K. Development of antigen cross-presentation capacity in dendritic cells. Trends Immunol 2012; 33:381-388.

21. Toes RE, Schoenberger SP, van der Voort EI, Offringa R, Melief CJ. CD40-CD40Ligand interactions and their role in cytotoxic T lymphocyte priming and anti-tumor immunity. Semin Immunol 1998; 10:443-448.

22. Tang D, Kang R, Coyne CB, Zeh HJ, Lotze MT. PAMPs and DAMPs: signal 0s that spur autophagy and immunity. Immunol Rev 2012; 249:158-175.

23. Chiantore MV, Mangino G, Zangrillo MS, Iuliano M, Affabris E, Fiorucci $\mathrm{G}$ et al. Role of the microenvironment in tumourigenesis: focus on virus-induced tumors. Curr Med Chem 2015; 22:958-974.

24. Gilboa E. The makings of a tumor rejection antigen. Immunity 1999; 11:263-270.

25. Kurts C, Robinson BW, Knolle PA. Cross-priming in health and disease. Nat Rev Immunol 2010; 10:403-414.
26. Zitvogel L, Regnault A, Lozier A, Wolfers J, Flament C, Tenza D et al. Eradication of established murine tumors using a novel cell-free vaccine: dendritic cell-derived exosomes. Nat Med 1998; 4:594-600.

27. Ribas A, Butterfield LH, Glaspy JA, Economou JS. Cancer immunotherapy using gene-modified dendritic cells. Curr Gene Ther 2002; 2:57-78.

28. Boczkowski D, Nair SK, Snyder D, Gilboa E. Dendritic cells pulsed with RNA are potent antigen-presenting cells in vitro and in vivo. J Exp Med 1996; 184:465-472.

29. Regnault A, Lankar D, Lacabanne V, Rodriguez A, Thery C, Rescigno $\mathrm{M}$ et al. Fcgamma receptor-mediated induction of dendritic cell maturation and major histocompatibility complex class I-restricted antigen presentation after immune complex internalization. J Exp Med 1999; 189:371-380.

30. Fong L, Engleman EG. Dendritic cells in cancer immunotherapy. Annu Rev Immunol 2000; 18:245-273.

31. Vives-Pi M, Rodríguez-Fernández S, Pujol-Autonell I. How apoptotic $\beta$-cells direct immune response to tolerance or to autoimmune diabetes: a review. Apoptosis 2015; 20:263-272.

32. Kerr JF, Wyllie AH, Currie AR. Apoptosis: a basic biological phenomenon with wide-ranging implications in tissue kinetics. $\mathrm{Br}$ J Cancer 1972; 26:239-257.

33. Wyllie AH, Kerr JF, Currie AR. Cell death: the significance of apoptosis. Int Rev Cytol 1980; 68:251-306.

34. Nagata S, Hanayama R, Kawane K. Autoimmunity and the clearance of dead cells. Cell 2010; 140:619-630.

35. Spel L, Boelens JJ, Nierkens S, Boes M. Antitumor immune responses mediated by dendritic cells: How signals derived from dying cancer cells drive antigen cross-presentation. Oncoimmunology 2013; 2:e26403.

36. Steinman RM, Turley S, Mellman I, Inaba K. The induction of tolerance by dendritic cells that have captured apoptotic cells. J Exp Med 2000; 191:411-416.

37. Morelli AE. The immune regulatory effect of apoptotic cells and exosomes on dendritic cells: its impact on transplantation. Am J Transplant 2006; 6:254-261.

38. Obeid M, Tesniere A, Ghiringhelli F, Fimia GM, Apetoh L, Perfettini JL et al. Calreticulin exposure dictates the immunogenicity of cancer cell death. Nat Med 2007; 13:54-61.

39. Green DR, Ferguson T, Zitvogel L, Kroemer G. Immunogenic and tolerogenic cell death. Nat Rev Immunol 2009; 9:353-363.

40. Kroemer G, Galluzzi L, Kepp O, Zitvogel L. Immunogenic cell death in cancer therapy. Annu Rev Immunol 2013; 31:51-72.

41. Krysko DV, Garg AD, Kaczmarek A, Krysko O, Agostinis P, Vandenabeele P. Immunogenic cell death and DAMPs in cancer therapy. Nat Rev Cancer 2012; 12:860-875.

42. Tesniere A, Panaretakis T, Kepp O, Apetoh L, Ghiringhelli F, Zitvogel L et al. Molecular characteristics of immunogenic cancer cell death. Cell Death Differ 2008; 15:3-12.

43. Strome SE, Voss S, Wilcox R, Wakefield TL, Tamada K, Flies D et al. Strategies for antigen loading of dendritic cells to enhance the antitumor immune response. Cancer Res 2002; 62:1884-1889.

44. Henry F, Boisteau O, Bretaudeau L, Lieubeau B, Meflah K, Grégoire M. Antigen-presenting cells that phagocytose apoptotic 
http://www.smartscitech.com/index.php/ccm

tumor-derived cells are potent tumor vaccines. Cancer Res 1999; 59:3329-3332.

45. Hoffmann TK, Meidenbauer N, Dworacki G, Kanaya H, Whiteside TL. Generation of tumor-specific T-lymphocytes by cross-priming with human dendritic cells ingesting apoptotic tumor cells. Cancer Res 2000; 60:3542-3549.

46. Sauter B, Albert ML, Francisco L, Larsson M, Somersan S, Bhardwaj N. Consequences of cell death: exposure to necrotic tumor cells, but not primary tissue cells or apoptotic cells, induces the maturation of immunostimulatory dendritic cells. J Exp Med 2000; 191:423-434.

47. Balkwill F, Mantovani A. Inflammation and cancer: back to Virchow? Lancet 2001; 357:539-545.

48. Hasan UA, Zannetti C, Parroche P, Goutagny N, Malfroy M, Roblot $\mathrm{G}$ et al. The human papillomavirus type 16 E7 oncoprotein induces a transcriptional repressor complex on the Toll-like receptor 9 promoter. J Exp Med 2013; 210:1369-1387.

49. Finch CE, Crimmins EM. Inflammatory exposure and historical changes in human life-spans. Science 2004; 305:1736-1739.

50. Tommasino $\mathrm{M}$. The human papillomavirus family and its role in carcinogenesis. Semin Cancer Biol 2014; 26C:13-21.

51. Moody CA, Laimins LA. Human papillomavirus oncoproteins: pathways to transformation. Nat Rev Cancer 2010; 10:550:560.

52. Kim J, Shin S, Subramaniam M, Bruinsma E, Kim TD, Hawse JR et al. Histone demethylase JARID1B/KDM5B is a corepressor of TIEG1/KLF10. Biochem Biophys Res Commun 2010; 401:412-416.

53. Zhang B, Laribee RN, Klemsz MJ, Roman A. Human papillomavirus type 16 E7 protein increases acetylation of histone H3 in human foreskin keratinocytes. Virology 2004; 329:189-198.

54. Rincon-Orozco B, Halec G, Rosenberger S, Muschik D, Nindl I, Bachmann A et al. Epigenetic silencing of interferon-kappa in human papillomavirus type 16-positive cells. Cancer Res 2009; 69:8718-8725.

55. Ridnour LA, Cheng RY, Switzer CH, Heinecke JL, Ambs S, Glynn S et al. Molecular pathways: toll-like receptors in the tumor microenvironment-poor prognosis or new therapeutic opportunity. Clin Cancer Res 2013; 19:1340-1346.

56. Karim R, Meyers C, Backendorf C, Ludigs K, Offringa R, van Ommen GJ et al. Human papillomavirus deregulates the response of a cellular network comprising of chemotactic and proinflammatory genes. PLoS One 2011; 6:e17848.

57. Reiser J, Hurst J, Voges M, Krauss $\mathrm{P}$, Münch $\mathrm{P}$, Iftner $\mathrm{T}$ et al. High-risk human papillomaviruses repress constitutive kappa interferon transcription via E6 to prevent pathogen recognition receptor and antiviral-gene expression. J Virol 2011; 85:11372-11380.

58. Zheng ZM, Wang X. Regulation of cellular miRNA expression by human papillomaviruses. Biochim Biophys Acta 2011; 1809:668-677.

59. Lajer CB, Garnæs E, Friis-Hansen L, Norrild B, Therkildsen MH, Glud $\mathrm{M}$ et al. The role of miRNAs in human papilloma virus (HPV)-associated cancers: bridging between HPV-related head and neck cancer and cervical cancer. Br J Cancer 2012; 106:1526-1534.

60. Palucka K, Ueno H, Banchereau J. Recent developments in cancer vaccines. J Immunol 2011; 186:1325-1331.

61. Klechevsky E, Banchereau J. Human dendritic cells subsets as targets and vectors for therapy. Ann N Y Acad Sci 2013; 1284:24-30.

62. Montagner S, Orlandi EM, Merante S, Monticelli S. The role of miRNAs in mast cells and other innate immune cells. Immunol Rev 2013; 253:12-24.

63. Monticelli S, Natoli G. Short-term memory of danger signals and environmental stimuli in immune cells. Nat Immunol 2013; 14:777-784.

64. Jurkin J, Schichl YM, Koeffel R, Bauer T, Richter S, Konradi S et al. miR-146a is differentially expressed by myeloid dendritic cell subsets and desensitizes cells to TLR2-dependent activation. J Immunol 2010; 184:4955-4965.

65. Liu Y, Chen Q, Song Y, Lai L, Wang J, Yu H et al. MicroRNA-98 negatively regulates IL-10 production and endotoxin tolerance in macrophages after LPS stimulation. FEBS Lett 2011; 585:1963-1968.

66. Fields RC, Shimizu K, Mulé JJ. Murine dendritic cells pulsed with whole tumor lysates mediate potent antitumor immune responses in vitro and in vivo. Proc Natl Acad Sci U S A 1998; 95:9482-9487.

67. Shimizu K, Fields RC, Giedlin M, Mulé JJ. Systemic administration of interleukin 2 enhances the therapeutic efficacy of dendritic cell-based tumor vaccines. Proc Natl Acad Sci U S A 1999; 96:2268-2273.

68. Vandenabeele P, Galluzzi L, Vanden Berghe T, Kroemer G. Molecular mechanisms of necroptosis: an ordered cellular explosion. Nat Rev Mol Cell Biol 2010; 11:700-714.

69. Schnurr M, Scholz C, Rothenfusser S, Galambos P, Dauer M, Röbe $\mathrm{J}$ et al. Apoptotic pancreatic tumor cells are superior to cell lysates in promoting cross-priming of cytotoxic $\mathrm{T}$ cells and activate NK and gammadelta $\mathrm{T}$ cells. Cancer Res 2002; 62:2347-2352.

70. Ferlazzo G, Semino C, Spaggiari GM, Meta M, Mingari MC, Melioli G. Dendritic cells efficiently cross-prime HLA class I-restricted cytolytic $\mathrm{T}$ lymphocytes when pulsed with both apoptotic and necrotic cells but not with soluble cell-derived lysates. Int Immunol 2000; 12:1741-1747.

71. Galetto A, Buttiglieri S, Forno S, Moro F, Mussa A, Matera L. Drug- and cell-mediated antitumor cytotoxicities modulate cross-presentation of tumor antigens by myeloid dendritic cells. Anticancer Drugs 2003; 14:833-843.

72. Brusa D, Garetto S, Chiorino G, Scatolini M, Migliore E, Camussi $\mathrm{G}$ et al. Post-apoptotic tumors are more palatable to dendritic cells and enhance their antigen cross-presentation activity. Vaccine 2008; 26:6422-6432.

73. Vogel S, Börger V, Peters C, Förster M, Liebfried P, Metzger K et al. Necrotic cell-derived high mobility group box 1 attracts antigen-presenting cells but inhibits hepatocyte growth factor-mediated tropism of mesenchymal stem cells for apoptotic cell death. Cell Death Differ 2015; doi:10.1038/cdd.2014.225.

74. Scaffidi P, Misteli T, Bianchi ME. Release of chromatin protein HMGB1 by necrotic cells triggers inflammation. Nature 2002; 418:191-195

75. Viac J, Schmitt D, Thivolet J. An immunoelectron microscopic 
localization of wart associated antigens present in human papilloma virus (HPV) infected cells. J Invest Dermatol 1978; 70:263-266.

76. Caldeira S, Zehbe I, Accardi R, Malanchi I, Dong W, Giarre M et al. The E6 and E7 proteins of the cutaneous human papillomavirus type 38 display transforming properties. J Virol 2003; 77:2195-2206

77. Yee C, Krishnan-Hewlett I, Baker CC, Schlegel R, Howley PM. Presence and expression of human papillomavirus sequences in human cervical carcinoma cell lines. Am J Pathol 1985; 119:361-366.

78. Livak KJ, Schmittgen TD. Analysis of relative gene expression data using real-time quantitative PCR and the 2(-Delta Delta C(T)) Method. Methods 2001; 25:402-408.

79. Taganov KD, Boldin MP, Chang KJ, Baltimore D. NF-kappaB-dependent induction of microRNA miR-146, an inhibitor targeted to signaling proteins of innate immune responses. Proc Natl Acad Sci U S A 2006; 103:12481-12486.

80. Bai Y, Qian C, Qian L, Ma F, Hou J, Chen Y et al. Integrin CD11b negatively regulates TLR9-triggered dendritic cell cross-priming by upregulating microRNA-146a. J Immunol 2012; 188:5293-5302.

81. Lu C, Huang X, Zhang X, Roensch K, Cao Q, Nakayama KI et al. miR-221 and miR-155 regulate human dendritic cell development, apoptosis, and IL-12 production through targeting of p27kip1, KPC1, and SOCS-1. Blood 2011; 117:4293-4303.

82. Dunand-Sauthier I, Santiago-Raber ML, Capponi L, Vejnar CE, Schaad O, Irla $\mathrm{M}$ et al. Silencing of c-Fos expression by microRNA-155 is critical for dendritic cell maturation and function. Blood 2011; 117:4490-4500.

83. Zhou H, Huang X, Cui H, Luo X, Tang Y, Chen S et al. miR-155 and its star-form partner miR-155* cooperatively regulate type I interferon production by human plasmacytoid dendritic cells. Blood 2010; 116:5885-5894.

84. Martinez-Nunez RT, Louafi F, Friedmann PS, Sanchez-Elsner T. MicroRNA-155 modulates the pathogen binding ability of dendritic cells (DCs) by down-regulation of DC-specific intercellular adhesion molecule-3 grabbing non-integrin (DC-SIGN). J Biol Chem 2009; 284:16334-16342.

85. Ceppi M, Pereira PM, Dunand-Sauthier I, Barras E, Reith W, Santos MA et al. MicroRNA-155 modulates the interleukin-1 signaling pathway in activated human monocyte-derived dendritic cells. Proc Natl Acad Sci U S A 2009; 106:2735-2740.
86. Busch $\mathrm{M}$, Zernecke A. microRNAs in the regulation of dendritic cell functions in inflammation and atherosclerosis. J Mol Med (Berl) 2012; 90:877-885.

87. Cheng P, Zhou J, Gabrilovich D. Regulation of dendritic cell differentiation and function by Notch and Wnt pathways. Immunol Rev 2010; 234:105-119.

88. Hashimi, Fulcher JA, Chang, Gov L, Wang S Lee B. MicroRNA profiling identifies miR-34a and miR-21 and their target genes JAG1 and WNT1 in the coordinate regulation of dendritic cell differentiation. Blood 2009; 114:404-414.

89. Fordham JB, Naqvi AR, Nares S. Regulation of miR-24, miR-30b, and miR-142-3p during macrophage and dendritic cell differentiation potentiates innate immunity. J Leukoc Biol 2015; doi:10.1189/jlb.1A1014-519RR.

90. Liang $\mathrm{X}$, Liu $\mathrm{Y}$, Mei S, Zhang $\mathrm{M}$, Xin J, Zhang $\mathrm{Y}$ et al. MicroRNA-22 impairs anti-tumor ability of dendritic cells by targeting p38. PLoS One 2015 10:e0121510.

91. Liu X, Zhan Z, Xu L, Ma F, Li $\mathrm{D}$, Guo $\mathrm{Z}$ et al. MicroRNA-148/152 impair innate response and antigen presentation of TLR-triggered dendritic cells by targeting CaMKII $\alpha$. J Immunol 2010 185:7244-7251.

92. Sun Y, Varambally S, Maher CA, Cao Q, Chockley P, Toubai T et al. Targeting of microRNA-142-3p in dendritic cells regulates endotoxin-induced mortality. Blood 2011; 117:6172-6183.

93. Tang $\mathrm{H}$, Jiang $\mathrm{H}$, Zheng $\mathrm{J}$, Li J, Wei $\mathrm{Y}$, Xu $\mathrm{G}$ et al. MicroRNA-106b regulates pro-allergic properties of dendritic cells and Th2 polarisation by targeting early growth response- 2 in vitro. Int Immunopharmacol 2015; doi: 10.1016/j.intimp.2015.03.043.

94. Liu Y, Li J, Xia W, Chen C, Zhu H, Chen J et al. MiR-200b modulates the properties of human monocyte-derived dendritic cells by targeting WASF3. Life Sci 2015; 122:26-36.

95. Heinz, Platzer B, Reisner PM, Jörgl A, Taschner S, Göbel F et al. Differential involvement of PU.1 and Id2 downstream of TGF-beta1 during Langerhans-cell commitment. Blood 2006 107:1445-1453.

96. Park H, Huang X, Lu C, Cairo Zhou X. MicroRNA-146a and microRNA-146b regulate human dendritic cell apoptosis and cytokine production by targeting TRAF6 and IRAK1 proteins. J Biol Chem 2015; 290:2831-2841.

97. Mi, Xu YP, Wang H, Qi RQ, Dong Z, Zhou L. Deletion of microRNA miR-223 increases Langerhans cell cross-presentation. Int J Biochem Cell Biol. 2013; 45:395-400. 